„, This is the pre-peer reviewed version of the following article: Remo Tietze, René Panzer, Thorben Starzynski, Chris Guhrenz, Florian Frenzel, Christian Würth, Ute Resch-Genger, Jan J. Weigand and Alexander Eychmüller (2018). Synthesis of NIR-emitting InAs-based core/shell quantum dots with the use of tripyrazolylarsane as arsenic precursor. Particle and Particle System Characterization, 2018, Volume 35, Issue 9, pp. 1800175, which has been published in final form at DOI:10.1002/ppsc.201800175.

This article may be used for non-commercial purposes in accordance with Wiley Terms and Conditions for Self-Archiving."

\title{
Synthesis of NIR-emitting InAs-based core/shell quantum dots with the use of tripyrazolylarsane as arsenic precursor
}

Remo Tietze,${ }^{[a]}$ René Panzer, ${ }^{[b]}$ Thorben Starzynski, ${ }^{[a]}$ Chris Guhrenz, ${ }^{[a]}$ Florian Frenzel, ${ }^{[c]}$ Christian Würth, ${ }^{[c]}$ Ute Resch-Genger, ${ }^{[c]}$ Jan J. Weigand, ${ }^{*[b]}$ and Alexander Eychmüller *[a]

Remo Tietze, Thorben Starzynski, Chris Guhrenz, Prof. Dr. Alexander Eychmüller Physical Chemistry, Technische Universität Dresden, Bergstraße 66b, 01062 Dresden, Germany

E-mail: alexander.eychmueller@chemie.tu-dresden.de

Dr. René Panzer, Prof. Dr. Jan J. Weigand

Inorganic Molecular Chemistry, Technische Universität Dresden, Mommsenstraße 4, 01062

Dresden, Germany

E-mail: jan.weigand@tu-dresden.de

Florian Frenzel, Dr. Christian Würth, Dr. Ute Resch-Genger

Division Biophotonics, Federal Institute for Materials Research and Testing (BAM), Richard-

Willstaetter-Str.11, 12489 Berlin, Germany

Keywords: InAs, [As] precursor, quantum dots, waste prevention, emission tuning

\begin{abstract}
Tris(3,5-dimethylpyrazolyl)arsane (1) is introduced as an low-cost and convenient to handle arsenic precursor for the straight forward synthesis of InAs quantum dots (QDs). Transamination of 1 with the solvent oleylamine (OLA $H)$ gives trioleylarsane $\left(\mathrm{As}(\mathrm{OLA})_{3}\right)$ which in the presence of the reducing agents DIBAL- $H$ or $\mathrm{P}(\mathrm{OLA})_{3}$ yields InAs QDs via a typical hot injection approach. The size of the obtained InAs core QDs are tuned by varying the reaction time, the amount of the applied reducing agent, or even more effectively by changing the indium and/or zinc halide precursors, $\mathrm{InX}_{3}$ and $\mathrm{ZnX}_{2}(\mathrm{Cl}, \mathrm{Br}$, or I). Passivation of the
\end{abstract}


resulting InAs particles with a protective $\mathrm{ZnS}$ or $\mathrm{ZnSe}$ shell results in improved photoluminescence (PL) of the core/shell QDs covering a spectral range between 600-1150 nm.

\section{Introduction}

In recent years group III-V semiconductor materials gained tremendous attention as less toxic surrogates for group II-VI nanomaterials in optoelectronic devices. ${ }^{[1-6]}$ Thereby, InAs QDs are one of the most promising candidates for near infrared (NIR) and short-wave IR applications, such as bio-imaging, ${ }^{[7-9]}$ photovoltaics, ${ }^{[10,11]}$ photodetectors, ${ }^{[12,13]}$ and lasers. ${ }^{[14,15]}$ Current synthetic approaches are challenging since hazardous As precursors, such as the highly pyrophoric and toxic tris(trimethylsilyl)arsane $\left(\mathrm{As}\left(\mathrm{SiMe}_{3}\right)_{3}\right)$ is required. Those materials can only be handled under intense safety precautions, since they are often air and moisture sensitive and, in addition, in some cases commercially not available. Nevertheless, $\operatorname{As}\left(\mathrm{SiMe}_{3}\right)_{3}$ is the most commonly used arsenic precursor ${ }^{[2,16]}$ besides the less reactive $\mathrm{As}\left(\mathrm{GeMe}_{3}\right)_{3}{ }^{[17]}$ or highly toxic $\mathrm{AsH}_{3} .^{[18]}$ Recently, SRIVASTAVA et al. ${ }^{[19]}$ and GRIGEL et al. ${ }^{[20]}$ highlighted tris(dimethylamino)arsane $\left(\mathrm{As}\left(\mathrm{NMe}_{2}\right)_{3}\right)$ as commercially available precursor for the facile synthesis of InAs QDs. Mechanistically, As $\left(\mathrm{NMe}_{2}\right)_{3}$ undergoes a transamination reaction with the solvent and reagent OLA $H$ to give $\operatorname{As}(\mathrm{OLA})_{3}$ under the release of three equivalents of flammable dimethylamine. The reaction of $\mathrm{As}(\mathrm{OLA})_{3}$ with $\mathrm{InCl}_{3}$ to $\mathrm{InAs}$ QDs does not proceed without the subsequent addition of a reducing agent for which typically DIBAL- $H^{[19]}$ and nowadays also $\mathrm{P}(\mathrm{OLA})_{3}{ }^{[20]}$ or a $N, N$-dimethylethylamine complex $\left(\mathrm{DMEA}-\mathrm{AlH}_{3}\right)^{[21]}$ are used. In the case of DIBAL- $H$ and DMEA-AlH ${ }_{3}$, the As- $\mathrm{N}$ bonds are cleaved to give in situ $(\mathrm{OLA})_{\mathrm{X}} \mathrm{AsH}_{3-\mathrm{x}}$ species which react with the indium precursor to InAs QDs. ${ }^{[22,23]}$ With the applied concentration of DIBAL- $H$ the size of InAs QDs can be tuned according to the method by SRIVASTAVA et al. ${ }^{[19]}$ In contrast, the approach by GRIGEL et al. ${ }^{[20]}$ applies in situ generated $\mathrm{P}(\mathrm{OLA})_{3}$ as reducing agent for the InAs QD synthesis (Scheme 1). This species is known to act both, as a remarkably efficient phosphorus precursor and reducing agent for the preparation of InP QDs. ${ }^{[24,25,26]}$ GRIGEL et al. ${ }^{[20]}$ pointed out that phase pure InAs QDs are obtained since 
$\mathrm{P}(\mathrm{OLA})_{3}$ only provides the electrons required for the reduction of $\mathrm{As}(\mathrm{OLA})_{3}$ to InAs (Scheme 1).

In previous work we introduced tripyrazolylphosphanes $\left(\mathrm{P}(\mathrm{pyr})_{3}, \quad\right.$ e.g., pyr $=3,5-$ dimethylpyrazole, 2 ) for the convenient preparation of a long term stable ( $>6$ months $) \mathrm{P}(\mathrm{OLA})_{3}$ stock solution and its application for the synthesis of highly emitting $\operatorname{InP} / \mathrm{ZnS}$ QDs. ${ }^{[5,6]}$ Derivatives of $\mathrm{P}(\mathrm{pyr})_{3}$ are accessible on a multigram scale and represent a safe to handle, less toxic surrogate for cancerogenic hexaalkylphosphorous triamide derivatives such as $\mathrm{P}\left(\mathrm{NMe}_{2}\right)_{3}$ and $\mathrm{P}\left(\mathrm{NEt}_{2}\right)_{3}$. Moreover, the release of corrosive, flammable, and gaseous dialkylamines $\left(\mathrm{Me}_{2} \mathrm{NH}, \mathrm{Et}_{2} \mathrm{NH}\right)$ during the transamination with OLA $H$ is prevented. The released pyrazoles can easily be recovered in high yields $(>94 \%)$ and reused for the precursor synthesis. The tripyrazolylarsane $\left(\operatorname{As}(\mathrm{pyr})_{3}\right.$, e.g., $\mathrm{pyr}=3,5$-dimethylpyrazole, 1$)$ analogues are envisioned to react similarly, thus, representing a convenient to handle and stable arsenic precursor for the InAs QD synthesis.

The expansion of our previous results on $\mathrm{P}(\mathrm{pyr})_{3}$ to the corresponding arsane derivative $\mathbf{1}$ for the synthesis of InAs QDs is topic of this contribution. For the initialization of the QD formation, DIBAL- $H$ or $\mathrm{P}(\mathrm{OLA})_{3}$ are used as reducing agents. In addition, the size of the resulting InAs particles are tuned by the used counter ions of the indium and zinc halides $(\mathrm{Cl}, \mathrm{Br}$, or $\mathrm{I})$ and the reaction time, which has also a significant impact on the stability and luminescent properties. An additional enhancement is achieved by applying a protective zinc-containing ( $\mathrm{ZnSe}, \mathrm{ZnS})$ passivating shell.

\section{Results and Discussion}

\subsection{Preparation of a $\operatorname{Pn}(\mathrm{OLA}) 3(\mathrm{Pn}=$ As or $\mathrm{P})$ stock solution}

Tripyrazolylpnictanes $\mathbf{1}$ and $\mathbf{2}$ are conveniently prepared via a modified procedure of FISCHER et al. ${ }^{[27]}$ by reacting the respective $\mathrm{PnCl}_{3}(\mathrm{Pn}=\mathrm{P}, \mathrm{As})$ with trimethylsilylpyrazole derivative 3 (Scheme 2). The reactions are best performed under solvent free conditions and the products are obtained analytically pure in excellent yields $(>98 \%)$ after removal of all volatiles. The 
dissolution of 1 and 2 in OLA $H$ yields stable $\operatorname{Pn}(\mathrm{OLA})_{3}$ stock solutions from which the 3,5dimethylpyrazole is recovered ( $>94 \%)$ by applying a vacuum treatment. The stock solution can be conveniently applied for the InAs QD synthesis by applying DIBAL- $H$ or $\mathrm{P}(\mathrm{OLA})_{3}$ as reducing agent.

\subsection{Synthesis of InAs core QDs with different reducing agents}

Reacting a $0.5 \mathrm{M} \mathrm{As}(\mathrm{OLA})_{3}$ stock solution with the In precursor according to a typical InAs hot injection synthesis without adding a reducing agent does not lead to the expected color change which is an indication for the particle formation. In contrast, following the procedure of SRIVASTAVA et al. ${ }^{[19]}$ and GRIGEL et al. ${ }^{[20]}$ initializes particle formation and growth. The simultaneous injection of both the arsenic precursor and the reducing agent DIBAL- $H^{[19]}$, yields InAs QDs. This is indicated by a color change of the reaction mixture to black (Scheme 3, synthetic route A (SR A)). In this approach, the addition of a $\mathrm{Zn}$ salt is not required. From spectroscopic investigations (Figure S1) the development of an excitonic feature at $\sim 700 \mathrm{~nm}$ is observed after a growth time of $10 \mathrm{~min}$. A shift up to $\sim 950 \mathrm{~nm}$ is achieved with an increased reaction time of $30 \mathrm{~min}$. A representative transmission electron microscopy (TEM) image of the resulting InAs particles is shown in Figure 1a. Additionally to the growth/reaction time, the amount of reducing agent plays an imperative role for tuning the InAs QD size (Figure 1b). For standard experiments in which the growth time was set to $15 \mathrm{~min}$. and all other parameters kept constant, a decreased injection volume of DIBAL- $H(200 \mu 1,1 \mathrm{M})$ shifts the first excitonic feature from $\sim 750 \mathrm{~nm}$ to $1200 \mathrm{~nm}$. Increasing the amount of DIBAL- $H$, however, leads to the formation of smaller QD sizes in accordance to observations by SRIVASTAVA et al ${ }^{[19]}$, which is attributed to a faster nucleation caused by a higher concentration of As-H species. X-ray diffraction (XRD) measurements (Figure 1c) of the produced InAs QDs are in agreement with the cubic zinc blende crystal structure of bulk InAs (JCPDS-No. 15-896).

In the second synthetic approach, which requires the addition of a $\mathrm{Zn}$ salt, the stock solution of As(OLA) 3 prepared from 1 was directly applied (Scheme 3, synthetic route B (SR B)). For 
comparison purpose, the synthetic parameters were kept almost identical for the InAs QD synthesis using either DIBAL-H (SR A) or P(OLA) 3 (SR B) as reducing agents. Typically, $\mathrm{InCl}_{3}$ and $\mathrm{ZnCl}_{2}$ are first dissolved in $\mathrm{OLA} H$ and heated under inert atmosphere to $190^{\circ} \mathrm{C}$. After the addition of the $\mathrm{As}(\mathrm{OLA})_{3}$ stock solution, three equivalents of $\mathrm{P}(\mathrm{OLA})_{3}$ are injected leading to an immediate color change of the reaction mixtures to black indicating the formation of InAs core QDs. NMR spectroscopic monitoring of the reaction mixture proves the successive depletion of $\mathrm{P}(\mathrm{OLA})_{3}\left(\delta_{(31 \mathrm{P})}=97 \mathrm{ppm}\right)$ and the formation of the phosphonium salt $\left[\mathrm{P}(\mathrm{OLA})_{4}\right][\mathrm{Cl}]\left(\delta_{(31 \mathrm{P})}=29 \mathrm{ppm}\right.$; Figure S2). This is in agreement with the discussed redox reaction (Scheme 1) and the validation of QD formation by XRD investigations (Figure S3). The continuous red shift in the corresponding absorption spectra (Figure 1d) is in accordance with the growth of the InAs QDs. After 10 min and similar to SR A, the first excitonic transition is clearly present at $\sim 725 \mathrm{~nm}$ which further shifts with time to $\sim 1000 \mathrm{~nm}$. The InAs QDs obtained according to SR B are phase pure and do not show any contamination with phosphorus, which was proven by ICP-OES measurements to determine the elemental composition (Table $\mathbf{S 1}$ ). Thus $\mathrm{InCl}_{3}$ preferentially reacts with $\mathrm{As}(\mathrm{OLA})_{3}$ to InAs.

Although zinc salts are not required for InAs following SR A, for SR B no QD formation is observed without the presence of zinc halides $\left(\mathrm{ZnX}_{2}, \mathrm{X}=\mathrm{Cl}, \mathrm{Br}\right.$, or I) suggesting that a Lewis acid activation of the phosphorus based reducing agent $\mathrm{P}(\mathrm{OLA})_{3}$ is required. Recent calculations by Laufersky et al. ${ }^{[28]}$ for the corresponding InP particles revealed that $\mathrm{ZnCl}_{2}$ rapidly activates the phosphorus atom in $\mathrm{P}(\mathrm{OLA})_{3}$, stabilizes energetically more favorable transition states, and promotes the formation of reduced In-P(I) species. As a consequence, a 5-fold excess of $\mathrm{ZnX}_{2}$ was added in our QD synthesis according to SR B in order to overcome the activation barrier for the formation of the InAs QD. From other investigations ${ }^{[25]}$ it is known that the presence of $\mathrm{In}$ and/or $\mathrm{Zn}$ halides $\left(\mathrm{InX}_{3}, \mathrm{ZnX}_{2} ; \mathrm{X}=\mathrm{Cl}, \mathrm{Br}\right.$, I) significantly influences the spectroscopic features by altering the size of the resulting particles. This observation is 
discussed in terms of halide anion adsorption at the QD surfaces. The addition of modifiers such as carboxylic acids during the synthesis prevents this by the beneficial formation of In(carboxylate) $)_{3}, \mathrm{Zn}$ (carboxylate $)_{2}$ and $\mathrm{HX}(\mathrm{X}=\mathrm{Cl}, \mathrm{Br}$, or I). During our $\mathbf{S R} \mathbf{B}$, the formation of HX can be excluded since the solvent OLA $H$ reacts as a base, thus, it can be anticipated that the present halides interact during the synthesis with the precursor and the QD surface. Similar assumptions have already been extensively studied for InP QDs using X-ray fluorescence spectroscopy (XRF). ${ }^{[25]}$ Based on these XRF measurements, the application of different indium and/or zinc halides should also directly influence the particle size growth and to the best of our knowledge this influence is now for the first time investigated on the synthesis for InAs QDs. Our SR B allows to investigate the influence, by the systematic change of the In and Zn metal halides $\mathrm{InX}_{3}$ and $\mathrm{ZnX}_{2}(\mathrm{X}=\mathrm{Cl}, \mathrm{Br}, \mathrm{I})$, on the size of the resulting InAs particles (Figure 2). While all other reaction parameters were kept the same $\left(190^{\circ} \mathrm{C}\right.$ injection and growth temperature, 15 min of growth time) the absorption is shifted from $\sim 540 \mathrm{~nm}$, to $\sim 650 \mathrm{~nm}$ to $\sim 820 \mathrm{~nm}$ for $\mathrm{ZnI}_{2}, \mathrm{ZnBr}_{2}$, and $\mathrm{ZnCl}_{2}$, respectively (Figure 2a). From TEM images shown in Figure 3 we determined the average size of core InAs particles synthesized with $\mathrm{ZnBr}_{2}$ and $\mathrm{ZnCl}_{2}$ to $3.5 \mathrm{~nm}$ and $5.1 \mathrm{~nm}$, respectively. This is the first literature report of a shift of the first excitonic transition of InAs QDs below $600 \mathrm{~nm}$. Typically, the first transition is located between $650 \mathrm{~nm}$ and $750 \mathrm{~nm}$ if $\mathrm{As}(\mathrm{TMS})_{3}{ }^{[27]}, \mathrm{AsH}_{3}{ }^{[18]}$ or $\mathrm{As}\left(\mathrm{NMe}_{2}\right)_{3}{ }^{[20]}$ are used as As precursors. Our investigations on the influence of the $\mathrm{In} \mathrm{X}_{3}$ precursor show a similar trend and absorption features at $\sim 810 \mathrm{~nm}, \sim 720 \mathrm{~nm}$, and $\sim 650 \mathrm{~nm}$ are observed applying the corresponding metal halides $\mathrm{InCl}_{3}, \mathrm{InBr}_{3}$ and $\mathrm{InI}_{3}$, respectively (Figure 2b). Based on these results, it can be concluded that the use of larger, i.e., more voluminous halide anions ( $\mathrm{I}>\mathrm{Br}>\mathrm{Cl}$ ) leads to a faster nucleation and, therefore, the formation of smaller InAs QDs similarly to the discussed effects elsewhere ${ }^{[25]}$ which is based on differences in the reaction rates as a result of the adsorption of the halide ions on the particle surface. 
In comparison to our results and to Laufersky et al, it can be rationalized that with increasing atom number of the halides $(\mathrm{Cl}>\mathrm{Br}>\mathrm{I})$ and the resulting reduced Lewis acidity of the $\mathrm{ZnX}_{2}$ $\left(\mathrm{ZnCl}_{2}>\mathrm{ZnBr}_{2}>\mathrm{ZnI}_{2}\right)$, the strength of the electronic interaction in the presumed phosphoruszinc halide complex is reduced which, consequently, speeds up the nucleation rate. For comparison, the results of both methods (SR A and SR B) are summarized in Table 1. Taking into account both reaction pathways, the QD size can be more easily tuned by the use of $\mathrm{P}(\mathrm{OLA})_{3}$ as reducing agent. Not only a broader absorption region is covered applying SR B but also the particle size can be more effectively controlled by changing the zinc and/or indium halide precursor. Since both approaches provide non-emitting core QDs, the following section focuses on the enhancement of the stability and PL properties of the InAs QDs by coating with a protective $\mathrm{ZnS}$ or $\mathrm{ZnSe}$ shell. The initial InAs particles were produced via SR B.

\subsection{Enhancement of the PL properties - shelling of InAs core QDs with ZnS(e)}

In order to render the InAs QDs luminescent, a protecting $\mathrm{ZnS}$ or $\mathrm{ZnSe}$ shell was directly grown on the non-emissive InAs cores which were synthesized according to SR B and without further purification. A stepwise increase of the reaction temperature and an alternating addition of $\mathrm{Zn}$ (stearate $)_{2}$ dissolved in 1-octadecene with stoichiometric amounts of a tri- $n$-octylphosphine sulfide (TOP-S) or selenide (TOP-Se) precursor resulted in the formation of either InAs/ZnS or InAs/ZnSe core/shell QDs. Figure $\mathbf{S 4}$ shows the corresponding absorption spectra of the initial InAs cores and the resulting InAs/ZnS QDs. A red shift of the first excitonic feature, which is distinctive for a type-I band alignment, indicates the successful growth of a $\mathrm{ZnS}$ shell. Another impressive evidence of the successful QD core passivation is the observed strong PL (Figure S5) with emission peaks at $937 \mathrm{~nm}$ and $1029 \mathrm{~nm}$ for $\mathrm{InAs} / \mathrm{ZnS}$ and $\mathrm{InAs} / \mathrm{ZnSe}$ QDs, respectively. The discrepancy of the emission maxima of $\mathrm{ZnS}$ - and $\mathrm{ZnSe}$-shelled nanomaterials is caused by differences in the band alignment of the resulting type-I core/shell structure. The mean fluorescence lifetimes of the resulting core/shell particles shelled with $\mathrm{ZnS}$ and $\mathrm{ZnSe}$ are determined to be $62 \mathrm{~ns}$ and $49 \mathrm{~ns}$ (Figure S6). The photoluminescence quantum yields (PL 
QYs) of both systems were determined to about $10 \%(\mathrm{InAs} / \mathrm{ZnS})$ and about $8 \%(\mathrm{InAs} / \mathrm{ZnSe})$. These values are comparable with the results obtained by GRIGEL et al. ${ }^{[20]}$ Additional XRD measurements (Figure S7) clearly indicate the formation of a passivating $\mathrm{ZnS}$ and $\mathrm{ZnSe}$ shell. Due to the high reaction temperatures an alloying process near the interface of the core and shell material shifts the (111) reflexes towards the pure zinc-containing shell material. This can be explained by a partial migration of zinc ions into the InAs core region, as it is also observed in the synthesis of InP/ZnS QDs. ${ }^{[5,6]}$ TEM measurements of the resulting spherical InAs/ZnS QDs exhibit an increase in the nanoparticle size compared to the original core particles and confirms additionally the growth of a ZnS protective layer (Figure S4). SR B results in a halide dependent InAs core size tuning, thus, subsequently, also the $\mathrm{ZnS}$ shelling of these QDs synthesized by using $\mathrm{ZnBr}_{2}$ and $\mathrm{ZnI}_{2}$ was investigated. The $\mathrm{PL}$ of the resulting InAs/ZnS QDs is shifted to shorter wavelengths applying $\mathrm{ZnBr}_{2}\left(\mathrm{PL}_{\max }\right.$ at $\left.770 \mathrm{~nm}\right)$ instead of $\mathrm{ZnCl}_{2}\left(\mathrm{PL}_{\max }\right.$ at $900 \mathrm{~nm}$ ) in accordance with a smaller core diameter (Figure 4a). However, attempts to obtain InAs/ZnS QDs using $\mathrm{ZnI}_{2}$ did not proceed. This might be caused by etching of the small InAs core particles during the shelling process.

In contrast, $\mathrm{ZnSe}$ coating of both InAs QDs synthesized from $\mathrm{ZnBr}_{2}$ and $\mathrm{ZnI}_{2}$ following $\mathbf{S R} \mathbf{B}$ was successful and the epitaxial shell growth shifts the emission towards $837 \mathrm{~nm}\left(\mathrm{ZnBr}_{2}\right)$ and even $604 \mathrm{~nm}\left(\mathrm{ZnI}_{2}\right.$; Figure 4b). Varying the initial InAs core size by changing the used $\mathrm{ZnX}_{2}$ precursor provides PL control over a broad wavelength region ranging from 600 to $1050 \mathrm{~nm}$ and shifts the emission even into the visible range.

\section{Conclusion}

In summary, the application of tris(3,5-dimethylpyrazolyl)arsane (1) as efficient As precursor for the InAs QD synthesis is presented. 1 undergoes an in situ transamination with the solvent OLA $H$ to yield a stable and easy to handle $\mathrm{As}(\mathrm{OLA})_{3}$ stock solution. During its preparation, the 3,5-dimethylpyrazole can be removed with high yield ( $>94 \%)$ by a vacuum treatment and 
reused in the synthesis of 1 . The resulting $\operatorname{As}(\mathrm{OLA})_{3}$ solution is applied in the InAs QD synthesis in the presence of the reducing agents DIBAL- $H$ and $\mathrm{P}(\mathrm{OLA})_{3}$ to initialize the $\mathrm{QD}$ formation and growth. The resulting InAs core size can be conveniently tuned from the visible to the NIR wavelength region $(\sim 540-1200 \mathrm{~nm})$ by varying the amount of DIBAL- $H$ according to $\mathbf{S R} \mathbf{A}$ or by changing the used metal halide $\left(\mathrm{InX}_{3}, \mathrm{ZnX}_{2} \mathrm{X}=\mathrm{Cl}, \mathrm{Br}, \mathrm{I}\right)$ by applying $\mathrm{P}(\mathrm{OLA})_{3}$ (SR B). Shelling of the non-emissive InAs core particles with $\mathrm{ZnS}$ or $\mathrm{ZnSe}$ encourages photoluminescence (PL) and the resulting core/shell QDs cover a broad spectral region ranging from $\sim 600 \mathrm{~nm}$ to $\sim 1200 \mathrm{~nm}$ with comparable high PL QYs reaching values of up to $10 \%$. 


\subsection{Experimental Section}

\section{Chemicals}

All chemicals used were of analytical grade or of the highest purity available. Indium chloride (Strem Chemicals, anhydrous, 99.99\%), indium bromide (Sigma Aldrich, 99\%), indium iodide (Sigma aldrich, 99.998\%), zinc chloride (Sigma Aldrich, anhydrous, 99.995\%), zinc bromide (Grüssing, anhydrous, 99\%), zinc iodide (Acros, anhydrous, 98\%), zinc stearate (Sigma Aldrich, purum), oleylamine (OLA $H$, Sigma Aldrich, 70\%), diisobutylaluminiumhydride (DIBAL- $H$, Sigma Aldrich, $1 \mathrm{M}$ solution in toluene), sulfur flakes (ABCR), selenium powder (Chempur, 160 mesh, 99.99\%), toluene (Sigma Aldrich, p.A.), and ethanol (technical grade). $\mathrm{AsCl}_{3}, \mathrm{PCl}_{3}$, 3,5-dimethylpyrazole and $\mathrm{Me}_{3} \mathrm{SiCl}$ were purchased from Sigma Aldrich. Dry, oxygen-free OLAH was distilled from $\mathrm{CaH}_{2}$ and stored under nitrogen. Deuterated benzene $\left(\mathrm{C}_{6} \mathrm{D}_{6}\right)$ was purchased from Sigma Aldrich and distilled from potassium. All glassware was oven-dried at $160^{\circ} \mathrm{C}$ prior to use. Tris(3,5-dimethylpyrazolyl)phosphane 2 and the $0.5 \mathrm{M} \mathrm{P}(\mathrm{OLA})_{3}$ stocksolution was obtained according to literature procedures. ${ }^{[5]}$

\section{Precursor Preparation}

Synthesis of tris(3,5-dimethyl)-1H-pyrazol-1-yl)arsane (1)

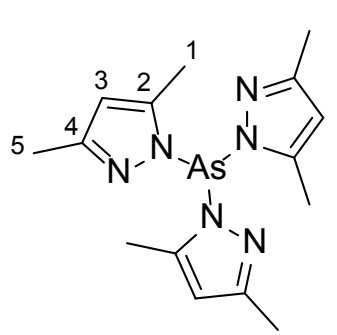

To a cooled solution $\left(0^{\circ} \mathrm{C}\right)$ of 1-(trimethylsilyl)-3,5-dimethyl- $1 H$ pyrazole $(18.9 \mathrm{~g}, 0.11 \mathrm{~mol})$ a solution of $\mathrm{AsCl}_{3}(0.57 \mathrm{~mL}, 6.81 \mathrm{mmol})$ is added dropwise. The reaction mixture is stirred at room temperature for $16 \mathrm{~h}$ and the colorless solid product $2(9.88 \mathrm{~g}, 98 \%)$ is obtained after the removal of all volatiles under vacuum.

Mp.: $105-109^{\circ} \mathrm{C}$; IR (KBr, $\left.300 \mathrm{~K},[\mathrm{~cm}-1]\right): v=3202(\mathrm{vw}), 3131(\mathrm{vw}), 3110(\mathrm{vw}), 3038(\mathrm{vw})$, 2976(vw), 2959(vw), 2931(m), 1561(vw), 1551(m), 1439(w), 1408(m), 1319(vw), 1295(vs), 1246(vw), 1152(w), 1109(m), 1018(w), 964(m), 801(w), 786(s), 754(w), 738(w), 587(w), 470(m), 461(w); ${ }^{1} \mathbf{H}$ NMR ( $\left.\mathrm{CD}_{2} \mathrm{Cl}_{2}, 300 \mathrm{~K},[\mathrm{ppm}]\right): \delta=2.02(9 \mathrm{H}, \mathrm{s}, \mathrm{C} 5-\mathrm{H}), 2.21(9 \mathrm{H}, \mathrm{s}, \mathrm{C} 1-$ 
$\mathrm{H}), 5.97(3 \mathrm{H}, \mathrm{m}, \mathrm{C} 3-\mathrm{H}) ;{ }^{13} \mathrm{C}$ NMR $\left(\mathrm{CD}_{2} \mathrm{Cl}_{2}, 300 \mathrm{~K},[\mathrm{ppm}]\right): \delta=11.3(3 \mathrm{C}, \mathrm{s}, \mathrm{C} 5), 13.8(3 \mathrm{C}, \mathrm{s}$, C1), 108.9 (s, 3C, C3), 147.5 (3C, s, C4), 152.9 (3C, s, C2); m/z (EI): 42(4), 81(5), 91(4), 95(28), 96(64), 97(8), 169(6), 170(20), 171(4), 264(6), 266(100), 267(12), 289(7), 360(3), 396(25). Elemental analysis: calc. for $\mathrm{C}_{15} \mathrm{H}_{21} \mathrm{AsN}_{6}$ : $23.3 \mathrm{~N}, 50.0 \mathrm{C}, 5.9 \mathrm{H}$ found: $23.2 \mathrm{~N}, 50.2$ C, $5.9 \mathrm{H}$.

InAs core QD synthesis

Synthesis of InAs core QDs with DIBAL-H - synthetic route A (SR A)

The InAs QD synthesis was performed with slight variations according to SRIVASTAVA et al. ${ }^{[19]}$ In a standard approach $0.2 \mathrm{mmol}$ of $\mathrm{InCl}_{3}(44.24 \mathrm{mg})$ and $5 \mathrm{~mL}$ of OLA $H$ are loaded in a 25 $\mathrm{mL}$ three-necked flask and vacuum was applied for $30 \mathrm{~min}$ at $120^{\circ} \mathrm{C}$. Under nitrogen atmosphere the temperature was increased to $250^{\circ} \mathrm{C}$. Simultaneously $0.4 \mathrm{~mL}(0.2 \mathrm{mmol})$ of a $0.5 \mathrm{~m}$ solution of $\mathrm{As}(\mathrm{OLA})_{3}$ and $1.2 \mathrm{~mL}$ of $1 \mathrm{M}$ DIBAL- $H$ in toluene (variation between $0.2 \mathrm{~mL}$ and $1.2 \mathrm{~mL}$ leads to different QD sizes) were injected rapidly into the reaction flask which results in a colored, i.e., black crude solution. The QDs were typically allowed to grow at $250^{\circ} \mathrm{C}$ for 5-30 min. Afterwards the reaction mixture was cooled to room temperature and diluted with $10 \mathrm{~mL}$ of toluene. $15 \mathrm{~mL}$ of ethanol were added to the crude solution to precipitate the QDs by centrifugation. The precipitated QDs were redispersed in toluene or TCE and centrifuged again to remove by-products of the InAs core synthesis. Following, the colloidal QD solution was additionally washed with ethanol and finally redispersed in toluene.

Synthesis of InAs core QDs with $P(O L A)_{3}$ - synthetic route B (SR B)

The procedure follows with slight variations GRIGEL et al. ${ }^{[20]}$ In a standard synthesis $0.2 \mathrm{mmol}$ (44.24 mg) of $\mathrm{InCl}_{3}, 4.4 \mathrm{mmol}$ of $\mathrm{Zn}(\mathrm{X})_{2}(\mathrm{X}=\mathrm{Cl}, \mathrm{Br}$, or I), and $5 \mathrm{~mL}$ of OLA $H$ were loaded in a $25 \mathrm{~mL}$ three-necked flask and vacuum was applied for $30 \mathrm{~min}$ at $120^{\circ} \mathrm{C}$. Following, the temperature was raised under inert atmosphere to $190^{\circ} \mathrm{C}$ and $0.2 \mathrm{mmol}(0.4 \mathrm{~mL})$ of a $0.5 \mathrm{M}$ 
solution of $\mathrm{As}(\mathrm{OLA})_{3}$ was injected into the reaction mixture. After $1 \mathrm{~min}$ of stirring $1.2 \mathrm{~mL}(0.6$ mmol) of a 0.5 M solution of $\mathrm{P}(\mathrm{OLA})_{3}$ was quickly injected to initialize the QD formation. The QDs were typically allowed to grow at $190^{\circ} \mathrm{C}$ for $15 \mathrm{~min}$. Afterwards the reaction mixture was cooled down to room temperature and diluted with $15 \mathrm{~mL}$ of ethanol to precipitate the QDs. The precipitated particles were redispersed in toluene and centrifuged again to separate from byproducts. The colloidal QD solution was cleaned once more by precipitation and dissolution using ethanol and toluene as non-solvent and solvent, respectively.

\section{ZnS(e) shelling procedure}

\section{ZnS shelling of InAs core QDs}

Typically the synthesis of InAs core QDs applying SR B is carried out for 15 min at $190^{\circ} \mathrm{C}$. For growing a $\mathrm{ZnS}$ shell the crude solution is kept at the reaction temperature and $1 \mathrm{~mL}$ of stoichiometric TOP-S (2.2 M) is slowly injected. After $60 \mathrm{~min}$ the temperature is increased from $190^{\circ} \mathrm{C}$ to $200^{\circ} \mathrm{C}$. At $120 \mathrm{~min} 1 \mathrm{~g}$ of $\mathrm{Zn}$ (stearate) 2 in $6 \mathrm{~mL}$ of ODE are slowly injected and the temperature is raised from $200^{\circ} \mathrm{C}$ to $220^{\circ} \mathrm{C}$. After $150 \mathrm{~min} 0.7 \mathrm{~mL}$ of TOP-S $(2.2 \mathrm{M})$ are injected and the reaction temperature is increased from $220^{\circ} \mathrm{C}$ to $240^{\circ} \mathrm{C}$. To increase the shell thickness $0.5 \mathrm{~g}$ of $\mathrm{Zn}$ (stearate) $)_{2}$ in $3 \mathrm{~mL}$ of ODE are slowly added after $180 \mathrm{~min}$ and the temperature is raised from $240^{\circ} \mathrm{C}$ to $260^{\circ} \mathrm{C}$. Finally, the synthesis of $\mathrm{InAs} / \mathrm{ZnS}$ core/shell QDs is quenched after 210 min and washed by precipitation with ethanol. The purified QDs are suspended in toluene. This procedures follows with slight variations GRIGEL et al. ${ }^{[20]}$

\section{ZnSe shelling of InAs core QDs}

Typically, InAs core QDs were grown for $15 \mathrm{~min}$ at $190^{\circ} \mathrm{C}$ applying SR B. Following, the resulting InAs core QDs were shelled with slight variations according to GRIGEL et al. ${ }^{[20]}$ The crude solution is kept at the initial reaction temperature of $190^{\circ} \mathrm{C}$ and $1 \mathrm{~mL}$ of stoichiometric TOP-Se $(2.2 \mathrm{M})$ is slowly injected. After stirring for $60 \mathrm{~min}$ the temperature is increased from 
$190^{\circ} \mathrm{C}$ to $200^{\circ} \mathrm{C}$. At $120 \mathrm{~min} 1 \mathrm{~g}$ of $\mathrm{Zn}$ (stearate) 2 in $6 \mathrm{~mL}$ of ODE are slowly injected and the temperature is raised from $200^{\circ} \mathrm{C}$ to $220^{\circ} \mathrm{C} .150 \mathrm{~min}$ after starting the shell growth $0.7 \mathrm{~mL}$ of TOP-Se $(2.2 \mathrm{M})$ are injected and the reaction temperature is increased from $220^{\circ} \mathrm{C}$ to $240^{\circ} \mathrm{C}$. Finally, $0.5 \mathrm{~g}$ of $\mathrm{Zn}$ (stearate) ${ }_{2}$ in $3 \mathrm{~mL}$ of ODE are slowly added after $180 \mathrm{~min}$ to increase the shell thickness and the temperature is additionally raised from $240^{\circ} \mathrm{C}$ to $260^{\circ} \mathrm{C}$. The synthesis of InAs/ZnSe QDs is quenched after 210 min shelling time and the crude solution is washed by using ethanol and toluene as non-solvent and solvent, respectively.

\section{Purification procedure of core/shell QDs}

To purify the core/shell QDs from byproducts, $15 \mathrm{~mL}$ of ethanol are added to the reaction mixture and centrifuged at $4500 \mathrm{rpm}$ for $5 \mathrm{~min}$. The supernatant is discarded and the precipitate is suspended in $4 \mathrm{~mL}$ of toluene or TCE depending on further processing. The QDs are redispersed by the use of ultrasonication and centrifuged at $3000 \mathrm{rpm}$ for $3 \mathrm{~min}$. The resulting supernatant is used for further characterization and processing.

\section{Characterization techniques}

Nuclear magnetic resonance (NMR) spectra were measured on a Bruker AVANCE III HD Nanobay $\left({ }^{1} \mathrm{H}(400.13 \mathrm{MHz}),{ }^{13} \mathrm{C}(100.61 \mathrm{MHz}),{ }^{31} \mathrm{P}(161.98 \mathrm{MHz})\right)$, on a $400 \mathrm{MHz}$ UltraSield, or on a Bruker AVANCE III HDX, $500 \mathrm{MHz}$ Ascend $\left({ }^{1} \mathrm{H}(500.13 \mathrm{MHz}),{ }^{13} \mathrm{C}(125.75 \mathrm{MHz})\right.$, $\left.{ }^{31} \mathrm{P}(202.45 \mathrm{MHz})\right)$. All ${ }^{13} \mathrm{C}$ NMR spectra were exclusively recorded with composite pulse decoupling. Chemical shifts $(\delta)$ were referenced to $\delta_{\mathrm{TMS}}=0.00 \mathrm{ppm}\left({ }^{1} \mathrm{H},{ }^{13} \mathrm{C}\right)$ and $\delta_{\mathrm{H} 3 \mathrm{PO} 4}(85 \%)$ $=0.00 \mathrm{ppm}\left({ }^{31} \mathrm{P}\right.$, externally) and are reported in ppm. Coupling constants $(\mathrm{J})$ are reported in $\mathrm{Hz}$.

Absolute PL QY measurements were performed with a calibrated integrating sphere setup equipped with a $450 \mathrm{~W}$ xenon lamp, coupled to a single monochromator as excitation channel. For QY determination, the luminescence intensity of dispersed InAs QDs was measured in the spectral range of $800-1150 \mathrm{~nm}$ using two detectors, a Si-CCD and an InGaAs-CCD, spectrally 
corrected, and subsequently integrated. ${ }^{[30,31]}$ The measurements were performed using $10 \mathrm{x} 4$ mm quartz cuvettes. The values of the absorbances of the dispersed InAs QDs at the excitation wavelength of $750 \mathrm{~nm}$ were between 0.08 and 0.1 .

UV/Vis absorption spectra of the QD solutions were recorded using a Cary 50 and Cary 5000 spectrophotometer (Varian).

PL spectra were measured on a FluoroLog-3 spectrofluorometer (Horiba Jobin Yvon Inc.) using variable excitation wavelength of 450 to $700 \mathrm{~nm}$ depending on the nature of the sample. The samples were prepared by dispersing the NCs in toluene or TCE depending on their spectroscopic features.

PL lifetimes were measured using a FluoroLog-3 spectrofluorometer (Horiba Jobin Yvon) equipped with a pulsed laser diode $(410 \mathrm{~nm})$ and a TCSPC module at room temperature. Average PL lifetimes were calculated at the time, where the initial signal intensity was reduced to 1000 counts/e.

Powder X-ray diffraction (XRD) patterns were collected in reflection mode with a Bruker

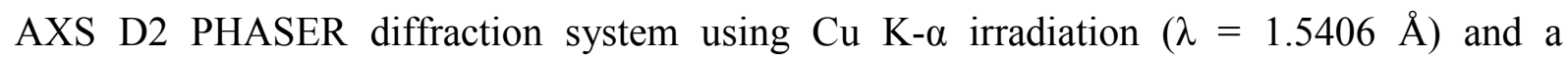
LYNXEYE/SSD160 detector.

Inductively coupled plasma-optical emission spectroscopy (ICP-OES) measurements were carried out on a Perkin-Elmer Optima 7000DV optical emission spectrometer. All calibration standard solutions were matrix matched. Concentrated aqua regia and deionized water were used to prepare the analyzing solutions.

Transmission electron microscopy (TEM) of the QDs was performed using a FEI Tecnai F30 microscope operated at $300 \mathrm{kV}$ and JEOL JEM-1400Plus microscope operated at $120 \mathrm{kV}$. 


\section{Supporting Information}

Supporting Information is available from the Wiley Online Library or from the author.

\section{Acknowledgements}

R.P. and J.J.W. gratefully acknowledge financial support from the European Research Council (ERC) (SynPhos, project number 307616). C.G., T.S., R.T. and A.E. are indebted to the DFG (ICENAP, GA 1289/3-1) and to the ERC (AdG 2013 AEROCAT) for funding of this research. The authors thank Susanne Goldberg and Annett Reichhelm for TEM measurements.

References

Received: ((will be filled in by the editorial staff))

Revised: ((will be filled in by the editorial staff)) Published online: ((will be filled in by the editorial staff))

[1] Y. W. Cao, U. Banin, Angew. Chemie - Int. Ed. 1999, 38, 3692.

[2] B. J. Beberwyck, A. P. Alivisatos, J. Am. Chem. Soc. 2012, 134, 19977.

[3] J. Lauth, T. Strupeit, A. Kornowski, H. Weller, Chem. Mater. 2013, 25, 1377.

[4] J. P. Park, J. J. Lee, S. W. Kim, J. Am. Chem. Soc. 2016, 138, 16568.

[5] R. Panzer, C. Guhrenz, D. Haubold, R. Hübner, N. Gaponik, A. Eychmüller, J. J. Weigand, Angew. Chemie - Int. Ed. 2017, 56, 14737.

[6] R. Panzer, C. Guhrenz, D. Haubold, R. Hübner, N. Gaponik, A. Eychmüller, J. J. Weigand, Angew. Chemie - Ger. Ed. 2017, 129, 14932.

[7] J. P. Zimmer, S. W. Kim, S. Ohnishi, E. Tanaka, J. V. Frangioni, M. G. Bawendi, J. Am. Chem. Soc. 2006, 128, 2526.

[8] D. Franke, D. K. Harris, O. Chen, O. T. Bruns, J. A. Carr, M. W. B. Wilson, M. G. Bawendi, Nat. Commun. 2016, 7, 12749.

[9] J. Gao, K. Chen, R. Xie, J. Xie, S. Lee, Z. Cheng, X. Peng, X. Chen, Small 2010, 6, 256.

[10] T. Sogabe, Y. Shoji, M. Ohba, K. Yoshida, R. Tamaki, H. F. Hong, C. H. Wu, C. T. Kuo, S. Tomić, Y. Okada, Sci. Rep. 2014, 4, 1. 
[11] D. M. Tex, I. Kamiya, Y. Kanemitsu, Sci. Rep. 2014, 4, 1.

[12] S. Maimon, E. Finkman, G. Bahir, S. E. Schacham, J. M. Garcia, P. M. Petroff, S. Maimon, E. Finkman, G. Bahir, Appl. Phys. Lett. 1998, 73, 2003.

[13] J. Miao, W. Hu, N. Guo, Z. Lu, X. Liu, L. Liao, P. Chen, T. Jiang, S. Wu, J. C. Ho, L. Wang, X. Chen, W. Lu, Small 2015, 11, 936.

[14] J. Y. Hsing, T. E. Tzeng, K. Y. Chuang, T. S. Lay, M. Y. Kuo, Y. Y. Tsai, K. S. Hsu, M. H. Shih, J. Cryst. Growth 2011, 323, 457.

[15] S. A. Sayid, I. P. Marko, S. J. Sweeney, P. Barrios, P. J. Poole, Appl. Phys. Lett. 2010, $97,1$.

[16] R. L. Wells, C. G. Pitt, A. T. Mcphail, A. P. Purdy, S. Shafieezad, R. B. Hallock, Chem. Mater. 1989, 1, 4.

[17] D. K. Harris, M. G. Bawendi, J. Am. Chem. Soc. 2012, 134, 20211.

[18] J. Zhang, D. Zhang, Chem. Mater. 2010, 22, 1579.

[19] V. Srivastava, E. M. Janke, B. T. Diroll, R. D. Schaller, D. V. Talapin, Chem. Mater. 2016, 28, 6797.

[20] V. Grigel, D. Dupont, K. De Nolf, Z. Hens, M. D. Tessier, J. Am. Chem. Soc. 2016, $138,13485$.

[21] V. Srivastava, E. Dunietz, V. Kamysbayev, J. S. Anderson, D. V. Talapin, Chem. Mater. 2018, DOI: 10.1021/acs.chemmater8b01137

[22] C. B. Lagrone, S. J. Schauer, C. J. Thomas, G. M. Gray, C. L. Watkins, L. K. Krannich, Organometallics 1996, 15, 3980.

[23] C. L. Watkins, L. K. Krannich, C. J. Thomas, D. Srivastava, Polyhedron 1994, 13, 3299.

[24] A. Buffard, S. Dreyfuss, B. Nadal, H. Heuclin, X. Xu, G. Patriarche, N. Mézailles, B. Dubertret, Chem. Mater. 2016, 28, 5925.

[25] M. D. Tessier, D. Dupont, K. De Nolf, J. De Roo, Z. Hens, Chem. Mater. 2015, 27, 
4893.

[26] M. D. Tessier, K. De Nolf, D. Dupont, D. Sinnaeve, J. De Roo, Z. Hens, J. Am. Chem. Soc. 2016, 138, 5923.

[27] S. Fischer, L. K. Peterson, J. F. Nixon, Can. J. Chem. 1974, 52, 3981.

[28] G. Laufersky, S. Bradley, E. Frecaut, M. Lein, T. Nann, Nanoscale 2018, 8, 1.

[29] A. A. Guzelian, U. Banin, A. V Kadavanich, X. Peng, A. P. Alivisatos, Appl. Phys. Lett. 1996, 69, 1432.

[30] S. Hatami, C. Würth, M. Kaiser, S. Leubner, S. Gabriel, L. Bahrig, V. Lesnyak, J. Pauli, N. Gaponik, A. Eychmüller, U. Resch-Genger, Nanoscale 2015, 7, 133.

[31] C. Würth, J. Pauli, C. Lochmann, M. Spieles, U. Resch-Genger, Anal. Chem. 2012, 84, 1345. 


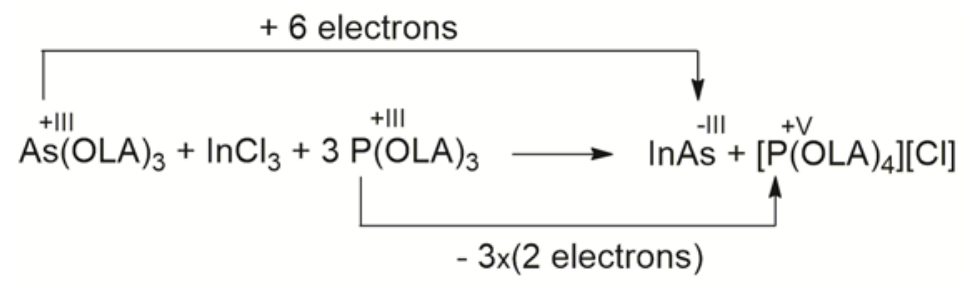

Scheme 1. Proposed redox reaction for the formation of InAs QDs applying $\mathrm{P}(\mathrm{OLA})_{3}$ as reducing agent. ${ }^{[20]} \mathrm{As}(\mathrm{OLA})_{3}$ and $\mathrm{P}(\mathrm{OLA})_{3}$ are formed in situ from the corresponding $\mathrm{Pn}\left(\mathrm{NMe}_{2}\right)_{3}(\mathrm{Pn}=\mathrm{As}$ or $\mathrm{P})$ precursors via transamination with OLA $H$.

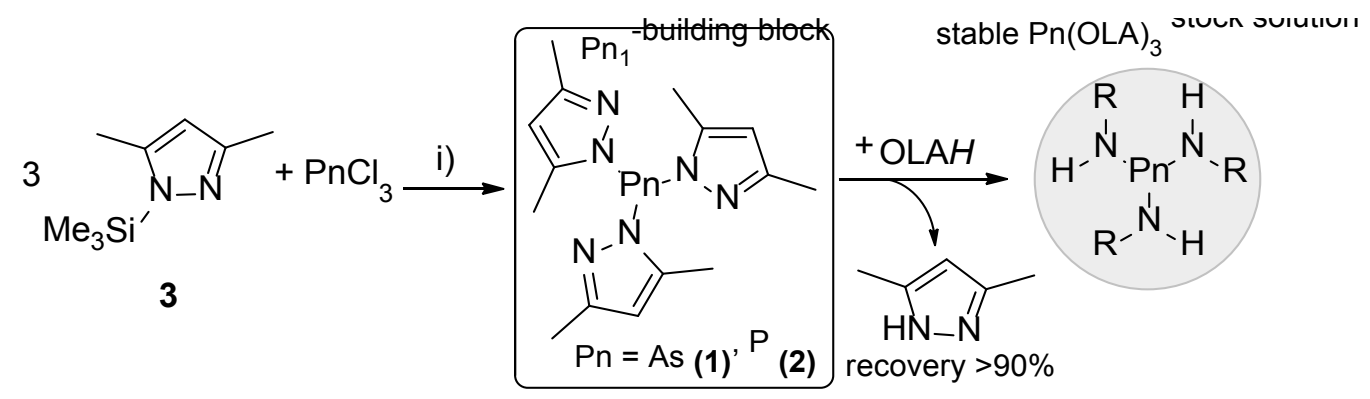

Scheme 2. Tris(3,5-dimethylpyrazolyl)arsane (1) and tris(3,5-dimethylpyrazolyl)phosphane (2) are synthesized via the reaction of trimethylsilylpyrazole (3) with $\mathrm{PnCl}_{3}(\mathrm{Pn}=\mathrm{As}, \mathrm{P})$, respectively; i) neat, $16 \mathrm{~h}$, room temperature. Dissolution of $\mathbf{1}$ and $\mathbf{2}$ in OLA $H$ yields under recovery of the pyrazole stable $\operatorname{Pn}(\mathrm{OLA})_{3}$ stock solutions.

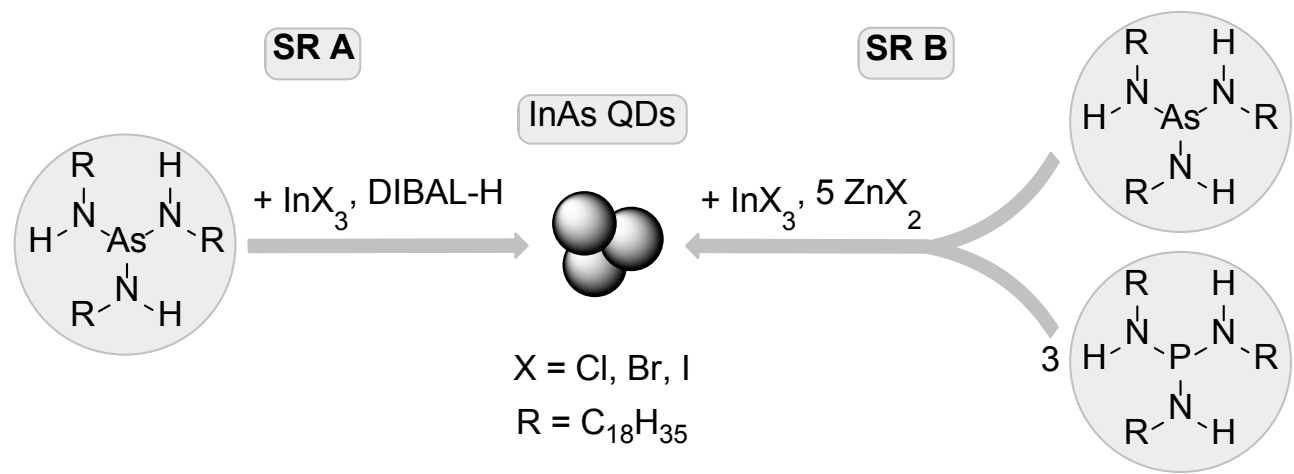

Scheme 3. Different synthetic approaches applied for the InAs QD formation using the previously prepared As(OLA) $)_{3}$ stock solution. Following SR A, DIBAL- $H$ is added as the reducing agent yielding InAs QDs. Applying SR B a zinc activation of the reducing agent $\mathrm{P}(\mathrm{OLA})_{3}$ is necessary to promote the formation of InAs QDs. 

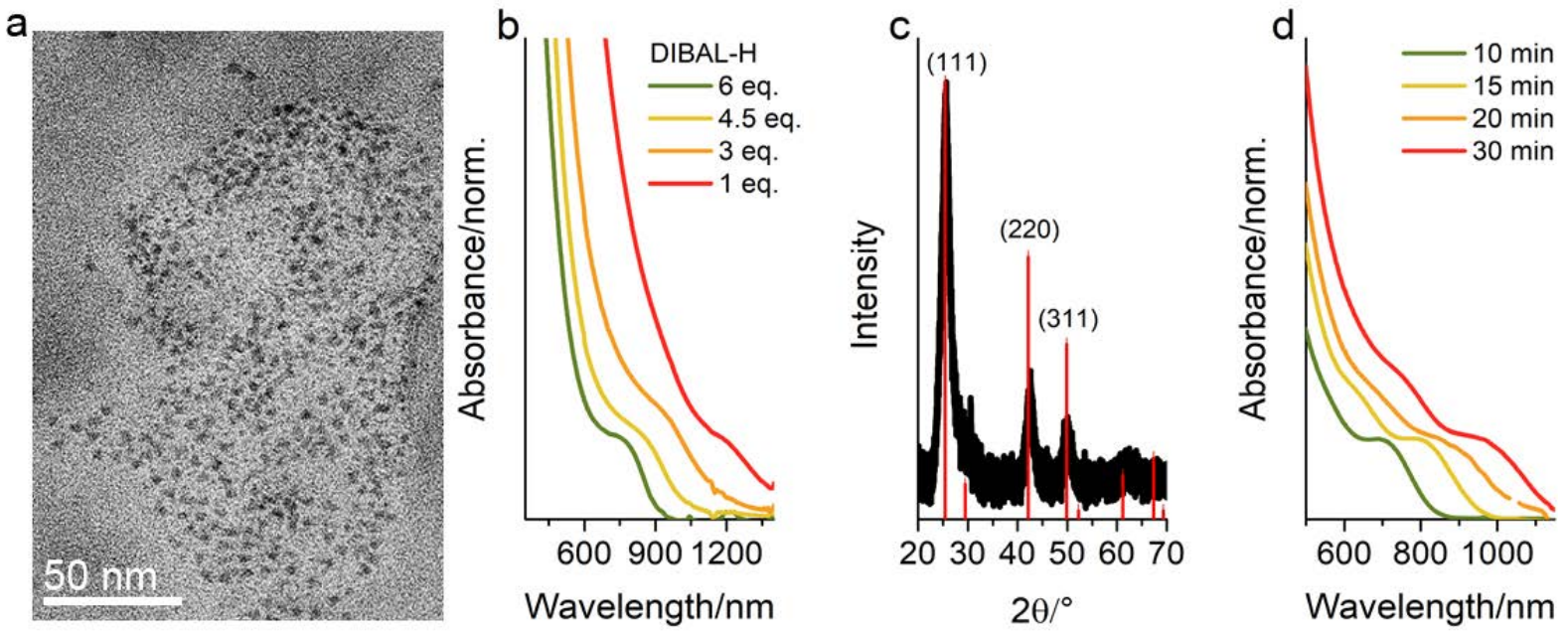

Figure 1. (a) Representative TEM image of InAs QDs synthesized with DIBAL- $H$ as reducing agent (SR A). (b) Shift of the absorption by varying the amount of reducing agent (DIBAL- $H$ ) used for the InAs QD synthesis and (c) confirmation of the cubic zinc blend structure (JCPDSNo. 15-896) of the resulting InAs QDs by XRD measurements. (d) Evolution of the excitonic absorption feature of the InAs QD synthesis with progressing reaction time applying $\mathrm{P}(\mathrm{OLA})_{3}$ as reducing agent (SR B).
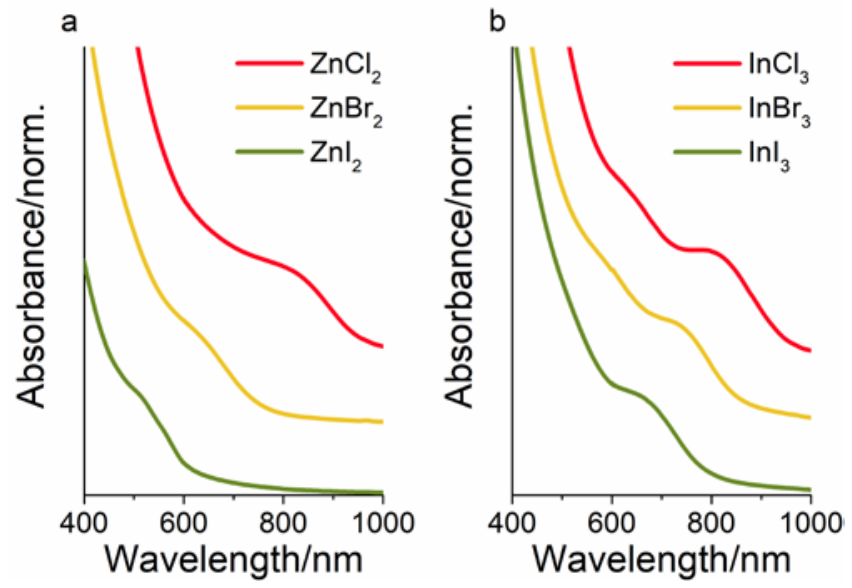

Figure 2. Variation of the used $\mathrm{ZnX}_{2}$ (a) and $\operatorname{InX} \mathrm{X}_{3}$ (b) for the InAs QD synthesis applying SR $\mathbf{B}(\mathrm{X}=\mathrm{Cl}, \mathrm{Br}, \mathrm{I})$; The observed blue shift in the absorption spectra correlates with an increase of the halide atomic number; the reaction time was set to $15 \mathrm{~min}$ and the injection and growth temperature to $190^{\circ} \mathrm{C}$; the concentration of $\mathrm{ZnX}_{2}$ (a) and $\mathrm{InX}_{3}$ (b) were kept constant.
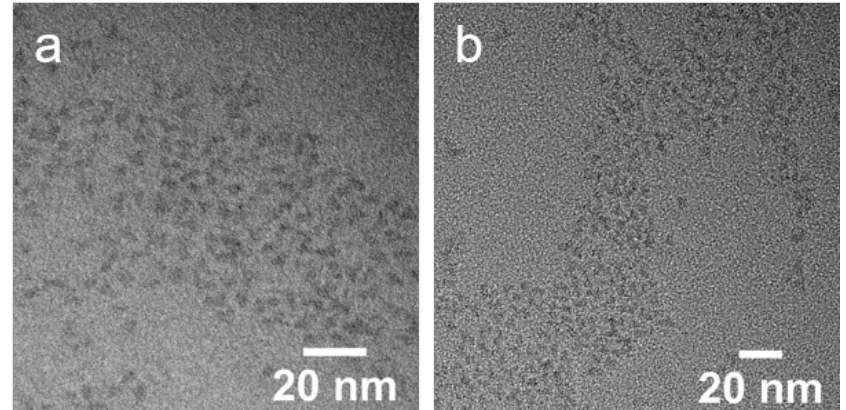

Figure 3. Representative TEM images of differently sized core InAs particles following SR B by the use of $\mathrm{ZnBr}_{2}$ (a) and $\mathrm{ZnCl}_{2}$ (b). The average size of the QDs has been determined to 3.5 $\mathrm{nm}(\mathrm{a})$ and $5.1 \mathrm{~nm}(\mathrm{~b})$. 
Table 1. Comparison of the absorption features applying both DIBAL-H (SR A) and $\mathrm{P}(\mathrm{OLA})_{3}$ (SR B) as reducing agents for the InAs QD synthesis.

\begin{tabular}{ccccc} 
Synthetic Route & SR A & \multicolumn{3}{c}{ SR B } \\
\hline & - & $\mathrm{ZnI}_{2}$ & $\mathrm{ZnBr}_{2}$ & $\mathrm{ZnCl}_{2}$ \\
\hline Absorption & $750-1200 \mathrm{~nm}$ & $540-620 \mathrm{~nm}$ & $610-715 \mathrm{~nm}$ & $700-1000 \mathrm{~nm}$ \\
& & & & \\
\hline
\end{tabular}
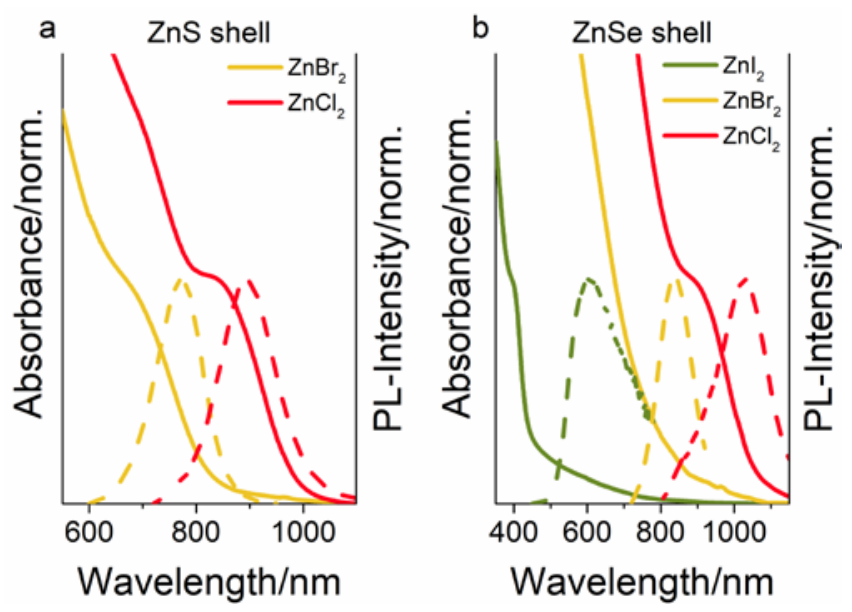

Figure 4. (a) Absorption and PL spectra of the resulting InAs/ZnS core/shell QDs applying SR $\mathrm{B}$ and $\mathrm{InCl}_{3}$ and different $\mathrm{ZnX} 2$ precursors for the core synthesis. (b) Absorption and PL spectra of the resulting $\mathrm{InAs} / \mathrm{ZnSe}$ core/shell QDs applying SR B and $\mathrm{InCl}_{3}$ and different $\mathrm{ZnX}_{2}$ precursors for the core synthesis. Due to a faster nucleation rate the spectra are blue-shifted with increasing atomic number. This shows the influence of the used zinc halide on the intial InAs core size and, in consequence, on the PL of the final core/shell strucure. 


\section{Table of contents entry:}

Core/shell InAs/ZnS(e) quantum dots covering a broad spectral region in the visible and near infrared (600-1050 nm) and reaching photoluminescence quantum yields of up to $10 \%$ were synthesized via two different reaction pathways using a tripyrazolylarsanes. The applied reducing reagent DIBAL- $H$ or $\mathrm{P}(\mathrm{OLA})_{3}$ in combination with different metal halides $\left(\operatorname{InX} \mathrm{X}_{3}\right.$, $\mathrm{ZnX}_{2}, \mathrm{X}=\mathrm{Cl}, \mathrm{Br}$, or I) allows an efficient tuning of the initial InAs core size and their photophysical properties.

Keyword: InAs, [As] precursor, quantum dots, waste prevention, emission tuning

Remo Tietze, René Panzer, Thorben Starzynski, Chris Guhrenz, Florian Frenzel, Christian Würth, Ute Resch-Genger, Jan J. Weigand and Alexander Eychmüller

Synthesis of NIR-emitting InAs-based core/shell quantum dots with the use of tripyrazolylarsane as arsenic precursor

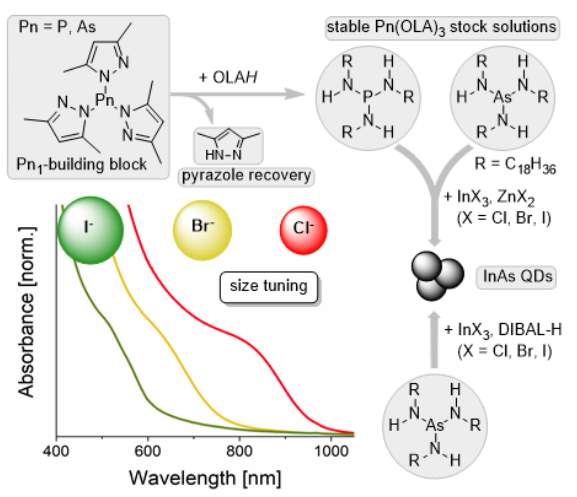

